\title{
Rijkskennisinstellingen op gepaste afstand
}

\author{
Gijs Diercks en Paul Diederen*
}

In oktober 2016 komt het tv-programma Zembla met een uitzending over kunstgraskorrels. Aanleiding is de zorg dat deze korrels mogelijk kankerverwekkend zijn. Het aantal kunstgrasvelden in Nederland steeg de afgelopen jaren explosief. $90 \%$ van die velden is bestrooid met gemalen autobanden - de zogeheten rubbergranulaatkorrels. De banden bevatten veel giftige stoffen. In 2006 liet de overheid nog weten dat er geen gezondheidsrisico's zijn voor mensen die op deze velden sporten. De Zembla-uitzending stelt hier echter vraagtekens bij: hoe goed zijn die risico's onderzocht? En zijn we wel goed en eerlijk geïnformeerd over de gezondheidsrisico's van kunstgrasvelden met gemalen autobanden? ${ }^{1}$

De uitzending leidt tot veel ophef, en toenmalig minister Schippers van Volksgezondheid, Welzijn en Sport geeft het RIVM opdracht om onderzoek te doen naar mogelijke gezondheidsrisico's van rubbergranulaat. De conclusie van het onderzoek is dat de gevolgen van sporten op deze kunstgrasvelden voor de gezondheid praktisch verwaarloosbaar zijn. ${ }^{2}$ Maar de twijfels blijven bestaan en het onderwerp is volop deel van het publieke debat. De geest is moeilijk terug in de fles te krijgen.

De kunstgraskorrels laten zien dat een op het eerste gezicht puur wetenschappelijk vraagstuk opeens onderdeel kan worden van maatschappelijk debat en daarmee politieke lading krijgt. Al snel gaat het debat dan over de betrouwbaarheid van kennis. Het voorbeeld van de kunstgraskorrels is niet uniek. Zo is de discussie over de noodzaak van HPV-vaccinaties bij meisjes van 14 inmiddels een bekend voorbeeld, net als de discussie over klimaatverandering. In beide gevallen stellen

* Dr. G. Diercks is als onderzoeker verbonden aan het Rathenau Instituut te Den Haag. Dr. P. Diederen is als themacoördinator werkzaam bij het Rathenau Instituut.

1 Zie https://zembla.bnnvara.nl/nieuws/kun-je-ziek-worden-van-kunstgras-die-vraag-stellen -ze-nu-ook-in-frankrijk.

2 Zie www.rivm.nl/rubbergranulaat/onderzoek-naar-rubbergranulaat-op-sportvelden. 
allerlei partijen vraagtekens bij wat kennisinstellingen presenteren als gevalideerde kennis.

In Nederland is het vertrouwen in de wetenschap hoog, maar dit vertrouwen is niet onvoorwaardelijk. Wetenschappers die werken in opdracht van overheden of bedrijven worden minder vertrouwd (Van den Broek-Honingh \& De Jonge 2018). Toch hebben overheden grote behoefte aan beleidsrelevant onderzoek. Een deel daarvan verkrijgt de overheid via de zogenoemde rijkskennisinstellingen (verkort: rki's): kennisorganisaties die ministeries ondersteunen bij de voorbereiding en uitvoering van beleid. Dat doen ze door onderzoek te doen of te laten doen.

In dit artikel richten we ons op deze rijkskennisinstellingen. De relatie tussen de rki's en de ministeries is in de loop van de tijd gegroeid. Er is geen overkoepelend (wettelijk) kader waarbinnen de onafhankelijkheid en integriteit zijn georganiseerd en geborgd. Het doel van dit artikel is om de diversiteit aan wettelijke regelingen en institutionele procedures in kaart te brengen, en te laten zien hoe dit tot uitdrukking komt in de praktijk van het onderzoek. De vraagstelling luidt: Hoe worden de onafhankelijkheid en integriteit van rijkskennisinstellingen in wettelijke regelingen en institutionele procedures georganiseerd en gewaarborgd, en hoe vertaalt zich dat in de praktijk van hun onderzoeksactiviteiten?

Dit artikel is als volgt opgebouwd. Eerst geven we kort methodologisch verantwoording van ons onderzoek. Vervolgens beschrijven we de groep rki's, en bieden een kader om naar deze organisaties te kijken. Daarna geven we antwoord op de onderzoeksvraag door te laten zien hoe onafhankelijkheid en integriteit van rki's in wettelijke regelingen en institutionele procedures zijn georganiseerd en gewaarborgd, en hoe zich dat vertaalt in de praktijk van het onderzoek. We sluiten af met een aantal concluderende observaties.

\section{Onderzoek naar onafhankelijkheid en integriteit door het Rathenau Instituut}

Het Netwerk van Rijkskennisinstellingen vroeg in de zomer van 2018 het Rathenau Instituut om in kaart te brengen hoe deze instellingen hun onafhankelijkheid en integriteit gewaarborgd hebben (Diercks e.a. 2018). Dit rki-netwerk is een samenwerking tussen dertien instel- 
lingen die functioneren op het snijvlak van kennis en beleid (zie tabel 1). De directe aanleiding voor het verzoek aan het Rathenau Instituut was een vermoedelijke inbreuk op de onafhankelijkheid van het WODC, aan het licht gebracht door een uitzending van Nieuwsuur. ${ }^{3}$ Dit leidde tot de instelling van drie onderzoekscommissies. Het centrale thema dat door de verschillende commissies werd geadresseerd, is de precaire balans tussen onafhankelijkheid en beleidsrelevantie, een thema dat bij alle rki's speelt. Dat het rki-netwerk naar aanleiding van de WODC-casus zijn eigen positie onder de loep wilde nemen, is daarom begrijpelijk.

Ons onderzoek strekte zich uit tot negen van de dertien leden van het rki-netwerk. ${ }^{4}$ Per instituut is een analyse gemaakt van de instellingsbeschikkingen en wettelijke regelingen, inclusief de toelichtingen hierop. Ook is een analyse gemaakt van specifieke regelingen en procedures waarin onafhankelijkheid en integriteit worden georganiseerd en gewaarborgd. Daarnaast zijn interviews gehouden met vertegenwoordigers van rki's over de wijze waarop onafhankelijkheid en integriteit worden opgevat bij het instituut, en wat de belangrijkste 'instrumenten' zijn om onafhankelijkheid en integriteit te organiseren en te borgen. Ook werd gevraagd naar specifieke gevallen en vormen van onderzoek waarin onafhankelijkheid en integriteit minder of juist meer onder druk komen te staan. Ten slotte zijn interviews gehouden met vertegenwoordigers van ministeries. Per rki is één beleidsmedewerker van het moederdepartement geïnterviewd over de visie van het betreffende ministerie op de onafhankelijkheid en integriteit van de betreffende rki. Hierin werd besproken welke regelingen en procedures er zijn om onafhankelijkheid en integriteit van de betreffende rki te borgen, en wat hun ervaringen hiermee zijn.

3 Zie https://nos.nl/nieuwsuur/artikel/2206290-onafhankelijk-onderzoeksinstituut-onder-druk -gezet-door-politiek.html.

4 Dit waren het Kennisinstituut voor Mobiliteitsbeleid (KiM), het Koninklijk Nederlands Meteorologisch Instituut (KNMI), het Nederlands Forensisch Instituut (NFI), het Nederlands Instituut voor Kunstgeschiedenis (RKD), de Nederlandse Voedsel- en Warenautoriteit (NVWA), de Rijksdienst voor het Cultureel Erfgoed (RCE), het Rijksinstituut voor Volksgezondheid en Milieu (RIVM), Rijkswaterstaat (RWS) en het Wetenschappelijk Onderzoeken Documentatiecentrum (WODC). 
Tabel 1 Een overzicht van alle rijkskennisinstellingen

\begin{tabular}{ll}
\hline Rijkskennisinstelling & Moederdepartement \\
\hline $\begin{array}{l}\text { Centraal Bureau voor de Statistiek } \\
\text { (CBS) }\end{array}$ & Economische Zaken en Klimaat \\
$\begin{array}{l}\text { Centraal Planbureau (CPB) } \\
\text { Kennisinstituut voor Mobiliteitsbeleid } \\
\text { (KiM) }\end{array}$ & $\begin{array}{l}\text { Economische Zaken en Klimaat } \\
\text { Infrastructuur en Waterstaat }\end{array}$ \\
$\begin{array}{l}\text { Koninklijk Nederlands Meteorologisch } \\
\text { Instituut (KNMI) }\end{array}$ & Infrastructuur en Waterstaat \\
$\begin{array}{l}\text { Nederlands Forensisch Instituut (NFI) } \\
\text { Nederlands Instituut voor Kunstge- }\end{array}$ & Justitie en Veiligheid \\
schiedenis (RKD) & Onderwijs, Cultuur en Wetenschap \\
$\begin{array}{l}\text { Nederlandse Voedsel- en Warenautori- } \\
\text { teit (NVWA) }\end{array}$ & \\
$\begin{array}{l}\text { Planbureau voor de Leefomgeving } \\
\text { (PBL) }\end{array}$ & Infrastructuur en Waterstaat \\
$\begin{array}{l}\text { Rijksdienst voor het Cultureel Erfgoed } \\
\text { (RCE) }\end{array}$ & Onderwijs, Cultuur en Wetenschap \\
$\begin{array}{l}\text { Rijksinstituut voor Volksgezondheid en } \\
\text { Milieu (RIVM) }\end{array}$ & Volksgezondheid, Welzijn en Sport \\
$\begin{array}{l}\text { Rijkswaterstaat (RWS) } \\
\text { Sociaal en Cultureel Planbureau (SCP) }\end{array}$ & Volksgezondheid, Welzijn en Sport \\
Wetenschappelijk Onderzoek- en & Justitie en Veiligheid \\
Documentatiecentrum (WODC) & \\
\hline
\end{tabular}

a De afkorting RKD staat voor de oude naam van de instelling: Rijksbureau voor Kunsthistorische Documentatie. Ondanks de verandering van de naam in Nederlands Instituut voor Kunstgeschiedenis blijft men de oude afkorting hanteren.

\section{Rijkskennisorganisaties verhouden zich tot beleid, wetenschap en samenleving}

Uit eerdere Rathenau Instituut-studies naar publieke kennisorganisaties, waaronder de rki's, blijkt dat deze moeten functioneren in relatie tot verschillende domeinen (Faasse \& Koens 2017). Die domeinen hebben elk hun eigen verwachtingen van de prestaties en kwaliteit van de kennisorganisatie. Ministeries zijn dus niet de enige stakeholders waartoe rki's zich hebben te verhouden. Ze verhouden zich ook tot de wetenschappelijke gemeenschap en moeten zich tevens verantwoorden naar de samenleving (zie figuur 1). 


\section{Figuur 1 Rijkskennisinstellingen (RKI) in context}

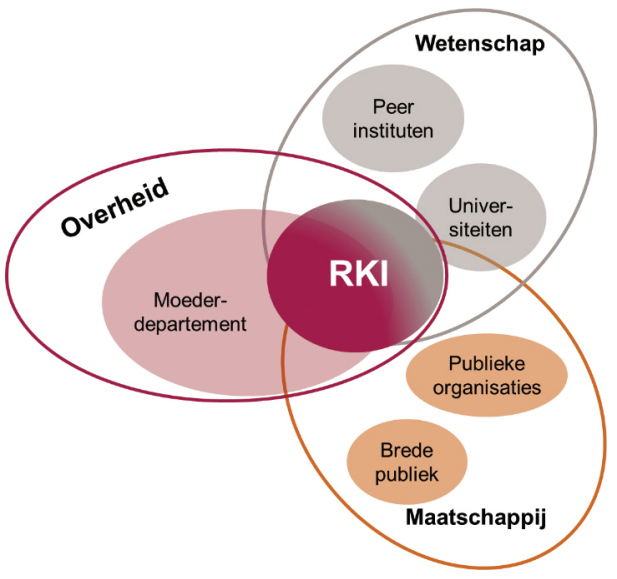

Niet elke rki bevindt zich op dezelfde centrale plek in deze figuur. Dat hoeft ook niet. Sommige instituten, bijvoorbeeld het KNMI en het RIVM, zijn zeer actief in de wetenschap en staan verder af van hun moederdepartement. Andere instituten, zoals Rijkswaterstaat en de Rijksdienst voor Cultureel Erfgoed, hebben een belangrijke rol in beleidsuitvoering, en hun onderzoek dient vooral als ondersteuning van deze hoofdtaak.

Toch is het belangrijk om de verschillende domeinen waartoe een rki zich verhoudt niet uit het oog te verliezen. Rki's moeten ervoor waken dat zij aansluiting blijven vinden bij de kennisbehoefte van het moederdepartement. Maar als ze zich in hun onderzoek te veel identificeren met het moederdepartement, bestaat het risico op 'beschuldiging van partijdigheid'.

Rki's kunnen hun onafhankelijkheid verstevigen door zich nadrukkelijker te verhouden tot het wetenschappelijke domein. Zo kunnen ze aantonen dat hun werk voldoet aan de standaarden die de wetenschap stelt, en dat het aansluit bij wetenschappelijke methoden en theorieën. Rki's kunnen hier dan ook regelingen voor treffen, zoals een onafhankelijke commissie die toezicht houdt op de wetenschappelijke kwaliteit van het onderzoek, het aannemen van onderzoekers met een deeltijdaanstelling aan een universiteit, of door de resultaten van hun werk te publiceren in de vorm van wetenschappelijke artikelen in peer reviewed tijdschriften. Een andere manier om de onafhankelijkheid te 
verstevigen is door zich nadrukkelijker te verhouden tot de maatschappij. Dit kan door vanuit de eigen organisatie en onafhankelijk te communiceren naar stakeholders en het brede publiek, bijvoorbeeld via de media.

Ministeries zijn vaak afhankelijk van kennis en informatie vanuit rki's. Tegelijkertijd moeten ze ervoor waken dat zij rki's niet behandelen als het eigen 'directoraat kennis'. Betrouwbaar beleidsrelevant onderzoek kan alleen tot stand komen wanneer rki's de ruimte hebben om de eisen van verschillende domeinen met elkaar te verenigen: het bestuurlijke, het wetenschappelijke en het maatschappelijke domein. Voor ministeries betekent dit dat onderzoek van rki's ook kan leiden tot uitkomsten die soms politiek niet opportuun zijn doordat deze het voorgestane beleid in meer of mindere mate ondergraven.

\section{Afspraken over onafhankelijkheid}

Beleidsgericht onderzoek kenmerkt zich door diverse vormen van afhankelijkheid. Om relevante onderzoeksvragen te formuleren is overleg nodig tussen beleidsambtenaren en onderzoekers. Hierdoor is absolute onafhankelijkheid niet alleen onhaalbaar, maar ook onwenselijk. Het zou kunnen leiden tot minder relevante vragen.

Onafhankelijkheid van onderzoek door rki's heeft daarom betrekking op specifieke aspecten van de samenwerkingsrelatie: de taakopvatting en rolverdeling, de verdeling van verantwoordelijkheden, en de afspraken die hierover gemaakt zijn. Voorbeelden van afspraken die we in onze analyse tegenkwamen, gaan over:

- de programmering. de opdrachtgever gaat over de onderzoeksvraag, de opdrachtnemer over de manier waarop die vraag beantwoord wordt (de keuze van onderzoeksmethode);

- de uitvoering. de opdrachtnemer gaat over de uitvoering van het onderzoek (de te raadplegen bronnen, de verzameling van empirische gegevens, de verwerking, de keuzes die tijdens het onderzoek worden gemaakt);

- de oordeelsvorming. de opdrachtnemer heeft de ruimte om aan de uitkomsten van het onderzoek een op wetenschappelijke gronden beargumenteerd oordeel te verbinden, het is aan de opdrachtgever om er eventueel een bestuurlijk of politiek oordeel aan te koppelen; 
- de disseminatie: de opdrachtnemer heeft de ruimte om resultaten zelfstandig te publiceren en te verspreiden, en over deze resultaten te communiceren.

Afspraken langs dit soort lijnen zijn gangbaar en kunnen op veel draagvlak rekenen bij zowel de rki's als de ministeries.

\section{Onafhankelijkheid in de praktijk}

Hoewel deze afspraken in theorie vrij duidelijke scheidslijnen suggereren, blijkt uit onze gesprekken dat rollen in de praktijk niet altijd zo helder gescheiden worden. Uiteraard komt onafhankelijkheid onder druk te staan als opdrachtgevers zich bemoeien met de aanpak van een onderzoek, met de inhoud van het rapport, of met de publicatie. Rechtstreekse bemoeienis met de aanpak, inhoud en publicatie zijn duidelijke gevallen van inbreuk op de onafhankelijkheid. Maar onafhankelijkheid kan ook op andere manieren worden aangetast. In elke fase van het onderzoek kan op subtiele(re) manieren sturing plaatsvinden. We lichten ze per fase toe.

\section{Programmering}

De opdrachtgever gaat over de onderzoeksvraag, maar wie gaat over de interpretatie en inkadering van de onderzoeksvraag, de afbakening daarvan, en de beslissing wat er niet onderzocht wordt? In hoeverre moet een onderzoeksinstelling de ruimte hebben zelf vragen te agenderen om werkelijk onafhankelijk te zijn, ook als het politiek even niet uitkomt?

Zo speelde programmering bijvoorbeeld een belangrijke rol in het geval van de kunstgraskorrels. Het RIVM had een paar jaar eerder al aangegeven deze korrels nader te willen onderzoeken, maar dit kreeg bij het ministerie geen prioriteit. Later moest het RIVM het onderzoek alsnog uitvoeren, maar dan 'in oorlogstijd': onder het oog van de samenleving en het vergrootglas van de media. 


\section{Uitvoering}

Hoewel de opdrachtgever niet over de onderzoeksaanpak gaat, bepaalt hij wel de randvoorwaarden. Ministeries stellen bijvoorbeeld grenzen door voor een onderzoek een bepaald budget uit te trekken en/of een doorlooptijd af te spreken. De opdrachtgever bepaalt dus niet hoe het onderzoek wordt uitgevoerd, maar wel is periodiek overleg over de voortgang tijdens de uitvoering gebruikelijk om te zorgen dat het onderzoek voldoet aan de behoeften. In dat proces kan druk worden uitgeoefend om het onderzoek bij te sturen.

Zo werd Rijkswaterstaat gevraagd om te inventariseren waar op de Nederlandse snelwegen de maximumsnelheid naar 130 kilometer per uur verhoogd kon worden. Dat de maximumsnelheid omhoog zou gaan, stond al vast. De effectiviteit van de maatregel of de wenselijkheid hiervan, bijvoorbeeld door het in kaart brengen van de potentiële tijdswinst of de extra milieubelasting, mocht daarom niet worden onderzocht. Intern leidde dit tot discussie.

\section{Oordeelsvorming}

De opdrachtnemer gaat over de wetenschappelijke conclusies en de opdrachtgever over de beleidsimplicaties. Maar wetenschappelijke conclusies hebben al snel een politieke lading. Tot hoever kan een onafhankelijke onderzoeksinstelling gaan, zonder op de stoel van de beleidsmaker te zitten?

Recent kwam de politieke gevoeligheid van oordeelsvorming zichtbaar naar voren in het nieuws bij de doorrekeningen van het Klimaatakkoord door het Planbureau voor de Leefomgeving (PBL). Het PBL was gevraagd een wetenschappelijke onderbouwing te geven voor goed geïnformeerd beleid in een beladen dossier. De doorrekeningen zullen onherroepelijk worden gebruikt om politieke keuzes te rechtvaardigen: hoe houdt het PBL voldoende afstand van het politieke debat, zodat het instituut niet te veel op de stoel van de beleidsmaker terechtkomt?

\section{Publicatie van onderzoeksresultaten}

De opdrachtnemer heeft afspraken gemaakt over het moment van publicatie, maar de opdrachtgever kan argumenten inbrengen om 
publicatie uit te stellen (bijvoorbeeld door te betwisten dat een onderzoek voldoet aan de afgesproken specificaties of via het stellen van aanvullende vragen). Zo geven gesprekspartners in de interviews aan dat er weinig tot geen gevallen zijn waarin een vraag leidt tot aanvullend onderzoek waarvan de publicatiedatum na een belangrijk Kamerdebat ligt. Onbedoeld heeft de onderzoeker de ambtenaar dan geholpen bij het uit de wind houden van de minister.

De voorbeelden laten zien dat onafhankelijkheid zoals deze op papier is vormgegeven, in de praktijk vaak weerbarstig is. Het is soms lastig om heldere scheidslijnen tussen de rollen van opdrachtgever en opdrachtnemer te trekken en die ook vast te houden. Dit is dan ook waar de belangrijkste spanningen optreden. Het gaat om het vinden van een acceptabele balans tussen betrokkenheid en onafhankelijkheid in de relatie tussen ministerie en rki, zonder dat eenduidig vaststaat wat goed gedrag is volgens de geformuleerde richtlijnen. Immers, je kunt a priori wel richtlijnen maken, maar praktische invulling daarvan zal per casus verschillen. Onafhankelijkheid vraagt om professionaliteit van beleidsmedewerkers én onderzoekers. Belangrijk zijn rolvastheid en respect voor de rol en verantwoordelijkheid van de ander. Onafhankelijkheid moet niet alleen worden geclaimd en bewaakt door de opdrachtnemer, maar ook door de opdrachtgever worden gegund en gerespecteerd.

\section{Integriteit als professioneel gedrag}

Onafhankelijkheid en integriteit zijn niet hetzelfde, maar hebben wel met elkaar te maken. Onafhankelijkheid is vrijheid van externe dwang. Integriteit is wanneer iemand eerlijk en oprecht en niet omkoopbaar is. De term onafhankelijkheid beschrijft een toestand: iemand is meer of minder onafhankelijk. Ministeries en rki's treffen voorzieningen om onafhankelijkheid te waarborgen. Integriteit heeft betrekking op (professioneel) gedrag, op de manier waarop een rki in de dagelijkse praktijk omgaat met het veiligstellen van onafhankelijkheid. Integriteit is het vermogen om druk te weerstaan en zich onafhankelijk te blijven opstellen. 
Wanneer het over integriteit in relatie tot onderzoek gaat, wordt meestal wetenschappelijke integriteit bedoeld. ${ }^{5}$ Wetenschappelijke integriteit betreft het in acht nemen van gedragsregels om onderzoek betrouwbaar en wetenschappelijk degelijk te laten zijn. Denk bijvoorbeeld aan het zich onthouden van plagiaat, geen fabricatie van resultaten of selectieve rapportage. In de relatie van ministeries en rki's is integriteit een breder begrip. Het gaat niet alleen om kwalitatief goede wetenschap, maar ook om de relevantie van het onderzoek. Het gaat om het juiste onderzoek op het juiste moment.

Binnen de afhankelijkheidsrelatie met de overheid is wetenschappelijke integriteit niet alleen het vermogen om weerstand te bieden aan druk om onderzoek te manipuleren. Integer handelen betekent ook weerstand bieden tegen druk om relevant onderzoek niet te doen, of juist weerstand te bieden tegen druk om vooringenomen of van opzet irrelevant onderzoek te doen, of om onderzoek 'onder de pet' te houden.

Net als onafhankelijkheid krijgt integriteit vorm in de relatie tussen opdrachtgever en opdrachtnemer. Het is een relatief begrip: onderzoekers beschikken over het vermogen om weerstand te bieden tegen druk, tot het moment dat de druk te hoog wordt. Druk kan worden opgevoerd - weerstandsvermogen is eindig. Rki's zijn verantwoordelijk voor het versterken van hun weerstandsvermogen en ministeries voor het reduceren van eventuele druk. De verantwoordelijkheid daarvoor ligt niet alleen bij onderzoekers en beleidsmedewerkers, maar ook bij de organisaties waarvoor zij werken.

\section{Onafhankelijkheid en integriteit vragen om 'harde' en 'zachte' vormen van borging}

In ons onderzoek zien we dat onafhankelijkheid en integriteit in de praktijk op verschillende manieren zijn georganiseerd. Er zijn 'harde' manieren van borging, die terug zijn te vinden op papier. Denk hierbij aan wettelijke bepalingen (instellingsbesluiten), positionering (plaatsing binnen of op afstand van ministeries) en geformaliseerde institutionele mechanismen als gedragscodes, protocollen, 'toezichtsarran-

5 Zie bijvoorbeeld de Nederlandse gedragscode wetenschappelijke integriteit (2018), uitgebracht door KNAW, NFU, NWO, TO2-federatie, VSNU en Vereniging Hogescholen: https://easy.dans.knaw.nl/ui/datasets/id/easy-dataset:110600/tab/2. 
gementen', adviesraden, betrokkenheid van externe experts, 'evaluatieregimes' en 'escalatiepaden'. Dat deze vormen van borging zijn ingesteld, betekent nog niet dat onafhankelijkheid daarmee geborgd is. Het gaat om het hoe: effectiviteit hangt af van details. Niet alleen óf een rki is ondergebracht binnen een ministerie heeft invloed op de onafhankelijkheid, maar ook het waar en hoe zijn van invloed. Het maakt uit of een rki ondergeschikt is aan een van de directoraten, of nevengeschikt is. Op diezelfde manier is het niet alleen van belang dat de minister de directeur van een rki benoemt, maar ook hoe de minister tot een keuze komt. Evenzeer is van belang hoe de opdracht aan een raad van advies luidt, hoe intensief een raad van toezicht betrokken is, en hoe een proces van instellingsevaluatie in elkaar steekt. Vormen van harde borging van onafhankelijkheid zijn een noodzakelijke, maar geen voldoende voorwaarde voor het vermogen om druk te kunnen weerstaan en integer te zijn. De 'zachte' borging is eveneens van belang, hoewel die vaak minder tastbaar is. Denk hierbij aan bewustwording, dialoog, opleiding en cultuur door inbedding in samenwerkingsrelaties en in omgangsvormen. Zachte borging komt tot uitdrukking in professioneel gedrag: het handelen vanuit een specifieke rol, het eerbiedigen van bijbehorende gedragscodes, het nemen van de verantwoordelijkheden die daarmee gepaard gaan, het bespreekbaar maken van optredende spanningen en bijbehorende dilemma's, en het elkaar aanspreken op professionaliteit. Dat vergt voldoende alertheid van zowel onderzoekers in de rol van opdrachtnemers als beleidsmedewerkers in de rol van opdrachtgevers. Om de noodzakelijke professionaliteit en alertheid op peil te houden zijn aandacht, dialoog en training vereist. Dit is niet alleen een zaak van individuele medewerkers van ministeries en rki's, maar ook van de betreffende organisaties als geheel.

\section{Conclusies}

Als een rki onderzoeksresultaten publiceert, is het van belang dat de ontvangers van deze resultaten erop kunnen vertrouwen dat ze kloppen. Gebeurt dit niet, dan gaat de discussie al snel over de onderliggende wetenschappelijke kennis, in plaats van over de politieke keuzes die op basis van deze kennis gemaakt moeten worden. Er mag dus geen aanleiding zijn om resultaten vooraf in twijfel te trekken, omdat 
er vanuit belangenoverwegingen gestuurd zou kunnen zijn op het onderzoek. Dat maakt onafhankelijkheid en integriteit van belang. Tegelijkertijd is het belangrijk dat activiteiten van rki's beantwoorden aan behoeften van de moederdepartementen. Ministeries hebben specifieke behoeften aan informatie en kennis, en rki's leveren die. Daarom is het van belang dat departementen in nauw contact staan met de rki's en hun behoeften duidelijk overbrengen.

\section{Een gedeelde verantwoordelijkheid}

Er bestaat een spanning tussen deze twee belangen: enerzijds is afstand tot de opdrachtgever gewenst omwille van de betrouwbaarheid van het onderzoek, en anderzijds is nauwe betrokkenheid nodig omwille van de relevantie. Een goede omgang met deze spanning vraagt niet alleen om formele regels, procedures en gedragscodes, maar ook om informele, meer 'culturele' zaken als rolvastheid en oog en respect voor de positie van de ander.

Onafhankelijkheid en integriteit krijgen vorm en betekenis in de relatie tussen ministerie en rki. Ze zijn hier samen verantwoordelijk voor. In de relatie tot elkaar moeten ze een juiste combinatie zien te vinden van onafhankelijkheid en betrokkenheid, ieder vanuit de eigen rol.

\section{Het thema staat bij rki's hoger op de agenda dan bij ministeries}

Rki's hebben recentelijk stappen genomen om onafhankelijkheid en integriteit beter te borgen, of zijn daarmee bezig. Het thema leeft. Ook bij de ministeries komt meer aandacht voor. Zo is eind 2017 een paragraaf toegevoegd aan de Gedragscode Integriteit Rijk (2017) over hoe er moet worden omgegaan met onderzoek. Toch constateren we in onze analyse een ongelijkheid in de relatie. Rki's lijken meer doordrongen van het belang dan ministeries. Hun reputatie staat of valt er immers bij. Hoewel ook ministeries het belang ervan onderkennen, vertaalt dit zich niet altijd in de implementatie van borgingsinstrumenten. Dit gebrek aan implementatie uit zich met name in de 'zachte' kant: bewustwording, dialoog, opleiding en cultuur. De verantwoordelijkheid voor het eerbiedigen van de onafhankelijkheid van rki-onderzoek 
komt hierdoor te liggen bij individuele beleidsmedewerkers, die zich soms lager en soms hoger in de departementale hiërarchie bevinden. ${ }^{6}$

\section{Wat werkt wel en wat werkt niet?}

Onafhankelijkheid van onderzoek door rki's is op diverse manieren gewaarborgd door positionering en protocollering. Maar the proof of the pudding is in the eating. de hamvraag is wat werkt in de gevallen waarin onafhankelijkheid in de praktijk onder druk komt te staan. Op basis van dit onderzoek kunnen we allereerst vaststellen wat niet werkt: vormen van borging die ver van de praktijk afstaan. Gedragscodes zijn belangrijk, maar werken niet als bijna niemand ze kent. Raden van toezicht kunnen hierin een taak vervullen, maar doen dat alleen als het waken over onafhankelijkheid en integriteit tot hun opdracht behoort. Vertrouwenspersonen hebben daarin ook een functie, maar kunnen die alleen waarmaken als de stap naar hen toe laagdrempelig is.

Wat ook niet werkt, is om rki's over één kam te scheren met universiteiten. Het is niet voldoende om alleen oog te hebben voor wetenschappelijke integriteit - hoe belangrijk deze ook is. Er dient ook oog te zijn voor de problematiek die specifiek is voor beleidsondersteunend onderzoek, waarbij de uitkomsten ook rekening moeten houden met de maatschappelijke en beleidscontext.

En wat werkt wel? In het algemeen heeft een combinatie van harde en zachte vormen van borging de beste kans van slagen. Het gaat om een combinatie van protocollen en gedragscodes, met maatregelen die bewustzijn bevorderen van de beleidscontext en politieke sensitiviteit.

6 Een andere blijk van de beperkte aandacht voor onafhankelijkheid van onderzoek zijn de algemene leveringsvoorwaarden voor diensten die de rijksoverheid hanteert, de Algemene Rijksvoorwaarden voor diensten 2018 (ARVODI-2018). Deze zijn in principe ook van toepassing op onderzoek, ofschoon ze daar niet in eerste instantie voor zijn gemaakt. Op diverse punten staan ze verder op gespannen voet met de Nederlandse Gedragscode Wetenschapsbeoefening, opgesteld door de VSNU (Vereniging van Universiteiten) en de Koninklijke Nederlandse Akademie van Wetenschappen (KNA)W. Deze leveringsvoorwaarden zijn niet van toepassing waar het gaat om onderzoek dat rki's zelf verrichten voor departementen (ze zijn immers onderdeel van de rijksoverheid), maar wel waar het onderzoek betreft dat ze uitbesteden aan derde partijen. 
Rki's op gepaste afstand

Kortom, om betrouwbaar onderzoek te kunnen leveren, moeten rki's zich onafhankelijk en integer kunnen opstellen. Een rki is meer dan een directoraat kennis van een ministerie. Departementen zijn niet de enige stakeholders waartoe rki's zich hebben te verhouden. Ze verhouden zich ook tot de wetenschappelijke gemeenschap en hebben zich tevens te verantwoorden naar de samenleving.

Maar om beleidsrelevant te zijn moeten rki's nauwe contacten met ministeries onderhouden. En om goed om te kunnen gaan met deze spanning zijn niet alleen 'harde' formele regels, procedures en gedragscodes nodig, maar ook 'zachte' informele zaken als bewustwording, dialoog, opleiding en cultuur. Rki's en ministeries zijn samen verantwoordelijk om hier vorm en betekenis aan te geven.

\section{Literatuur}

\section{Van den Broek-Honingh \& De Jonge 2018}

N. van den Broek-Honingh \& J. de Jonge, Vertrouwen in de wetenschap 2018, Den Haag: Rathenau Instituut 2018.

\section{Diercks e.a. 2018}

G. Diercks, P. Faasse, B. van der Meulen \& P. Diederen, Met gepaste afstand.

Onafhankelijkheid en integriteit bij onderzoek door rki's, Den Haag: Rathenau Instituut 2018.

\section{Faasse \& Koens 2017}

P. Faasse \& L. Koens, Gezond verstand. Publieke kennisorganisaties in de gezondheidszorg, Den Haag: Rathenau Instituut 2017.

\section{Gedragscode Integriteit Rijk 2017}

Gedragscode Integriteit Rijk, Den Haag: Ministerie van Binnenlandse Zaken en Koninkrijksrelaties 2017, www.rijksoverheid.nl/ documenten/richtlijnen/2017/ 12/01/gedragscode-integriteitrijk-gir. 